Landslides (2022) 19:491-503

DOI 10.1007/s10346-021-01747-w

Received: 19 March 2021

Accepted: 28 July 2021

Published online: 2 November 2021

(c) The Author(s) 2021
Ramtin Sabeti ${ }^{\circledR} \cdot$ Mohammad Heidarzadeh

\section{A new empirical equation for predicting the maximum initial amplitude of submarine landslide-generated waves}

Abstract The accurate prediction of landslide tsunami amplitudes has been a challenging task given large uncertainties associated with landslide parameters and often the lack of enough information of geological and rheological characteristics. In this context, physical modelling and empirical equations have been instrumental in developing landslide tsunami science and engineering. This study is focused on developing a new empirical equation for estimating the maximum initial landslide tsunami amplitude for solid-block submarine mass movements. We are motivated by the fact that the predictions made by existing equations were divided by a few orders of magnitude $\left(10^{-1}-10^{4} \mathrm{~m}\right)$. Here, we restrict ourselves to three main landslide parameters while deriving the new predictive equation: initial submergence depth, landslide volume and slope angle. Both laboratory and field data are used to derive the new empirical equation. As existing laboratory data was not comprehensive, we conduct laboratory experiments to produce new data. By applying the genetic algorithm approach and considering non-dimensional parameters, we develop and examine 14 empirical equations for the non-dimensional form of the maximum initial tsunami amplitude. The normalized root mean square error (NRMSE) index between observations and calculations is used to choose the best equation. Our proposed empirical equation successfully reproduces both laboratory and field data. This equation can be used to provide a preliminary and rapid estimate of the potential hazards associated with submarine landslides using limited landslide parameters.

Keywords Experimental fluid mechanics $\cdot$ Hydraulic engineering $\cdot$ Landslide $\cdot$ Landslide-generated waves $\cdot$ Tsunami

Introduction and literature review

Landslide-generated tsunamis have been at the centre of attention within the scientific community in recent years; this is particularly true following the September 2018 Palu (Indonesia) (Takagi et al. 2019; Gusman et al. 2019) (Fig. 1b) and December 2018 Anak Krakatau tsunamis (Grilli et al. 2019; Heidarzadeh et al. 2020), which together left more than 2000 deaths. Another significant landslide tsunami occurred in Papua New Guinea (PNG) in July 1998, which generated a maximum run-up of $15 \mathrm{~m}$, causing more than 2100 casualties (Synolakis et al. 2002; Tappin et al. 2008) (Fig. 1c). In addition, an on-land earthquake in Pakistan generated a landslide tsunami in September 2013 (Fig. 1a; Heidarzadeh and Satake 2014).

The accurate prediction of the maximum initial amplitude of landslide waves around the source region is an important hazard indicator for coastal impact assessment and proper modelling of the propagation and inundation of landslide tsunamis. In general, there are three different approaches to characterize the waves generated by submarine failures, comprising numerical simulations (e.g. Sassa et al. 2016; Løvholt et al. 2020), analytical calculations (e.g. Harbitz and Pedersen 1992) and physical modelling (e.g. Gómez et al. 2016). Due to the complexities associated with two-phase flows including water and solid involved in the evolution of landslide-generated waves, empirical equations proved beneficial for predicting the initial maximum amplitudes of the waves (Synolakis 2003; Watts et al. 2005; Sabeti and Heidarzadeh 2020). A large body of research on the subject is associated with physical modelling of the phenomenon through two-dimensional solid blocks sliding down a plane slope (e.g. Wiegel 1955; Iwasaki 1982; Heinrich 1992; Watts 1998; Grilli and Watts 2005; Najafi-Jilani and Ataie-Ashtiani 2008; FernándezNieto et al. 2008; Tinti and Tonini 2013). In addition, other researchers conducted three-dimensional physical modelling (e.g. Synolakis and Raichlen 2003; Liu et al. 2005).

A few researchers have proposed empirical equations for the prediction of the maximum initial landslide tsunami amplitudes $\left(\eta_{\max }\right)$; this is the maximum amplitude, either negative, $\eta_{\max , \mathrm{n}}$, or positive, $\eta_{\text {max,p }}$, of the landslide-generated waves around the source region after the generation phase. The majority of submarine landslide studies have considered $\eta_{\max , \mathrm{n}}$ for investigating the subject (Fig. 2). Table 1 presents a few such predictive equations while the full list is given in Sabeti and Heidarzadeh (2020). There are six main landslide parameters that affect $\eta_{\max , n}$ : the slide specific gravity $\left(\gamma_{s}\right)$, initial submergence depth $(d)$, slide length $(B)$, width $(w)$, thickness $(T)$ and slope angle $(\theta)$ (Fig. 2b). Murty's (2003) equation requires only three of these initial landslide parameters, whereas those equations of Watts et al. (2005) and Harbitz and Pedersen (1992) require four/ five input parameters. The performance of the existing predictive equations was assessed by Sabeti and Heidarzadeh (2020). It was shown that the $\eta_{\max , \mathrm{n}}$ predictions made by different equations are divided by a few orders of magnitude $\left(10^{-1}-10^{4} \mathrm{~m}\right)$; therefore, it is essential to conduct further studies on this topic.

The objective of this research is to develop a new empirical equation for predicting the maximum initial wave amplitude generated by a solid-block submarine landslide incorporating a few main landslide parameters. A motivation for this research is the lack of credible empirical equations in the literature for submarine landslide tsunamis, although more works have been done on subaerial landslides in the past decades. We use available experimental and field data from the literature along with some new laboratory data generated by our physical experiments to derive the new equation. In comparison to a previous study by Sabeti and Heidarzadeh (2020), in which they solely used field data from past landslide tsunamis, in the current study, we conduct new laboratory experiments 


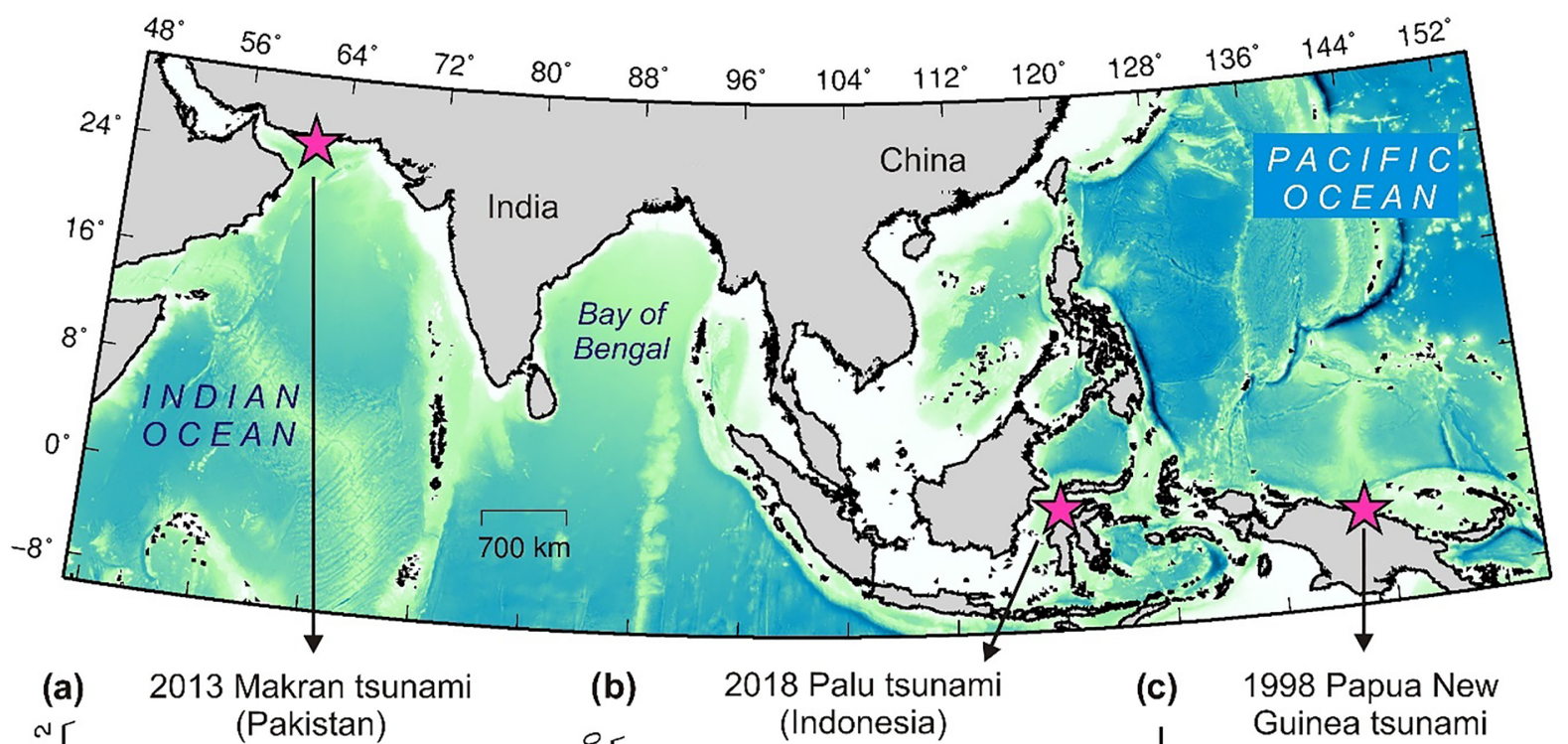

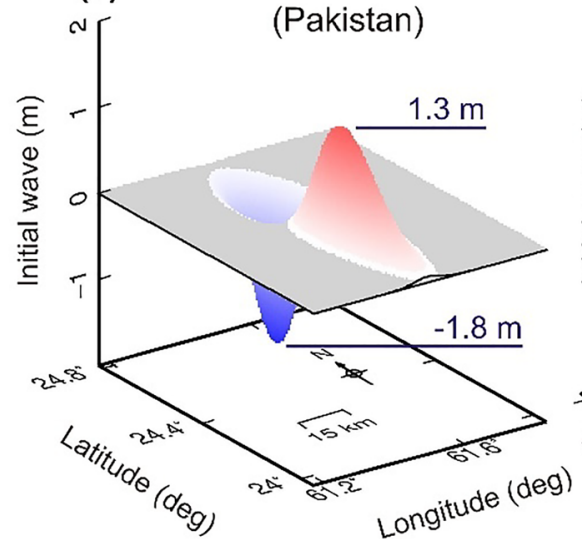

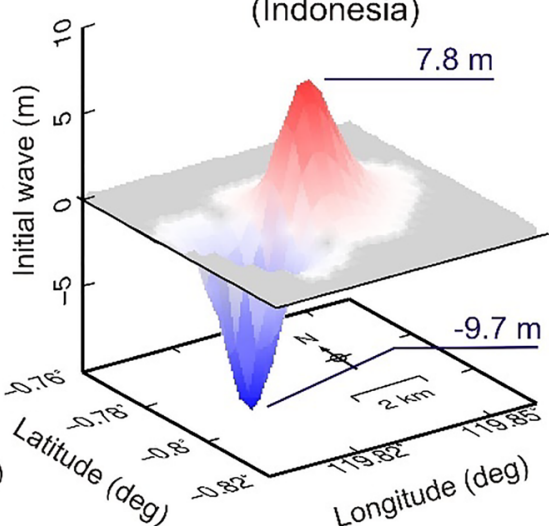

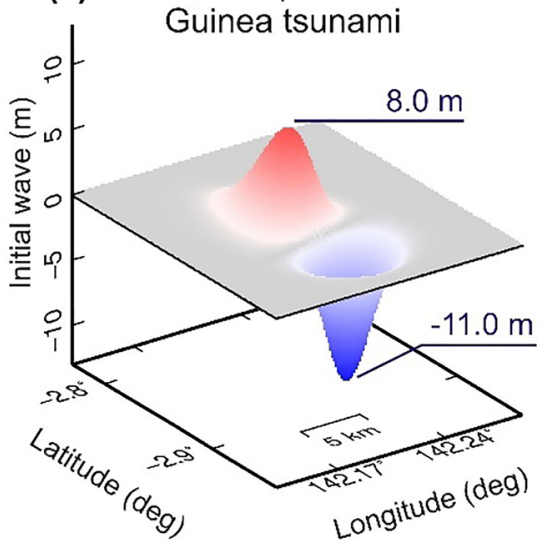

Fig. 1 The initial waves generated by worldwide submarine landslide tsunamis (a) in the Makran region of the NW Indian Ocean during the 2013 Pakistan tsunami, (b) in Palu, Indonesia, during the September 2018 tsunami and (c) in Papua New Guinea during the 1998 tsunami. The data of the panels (a) and (c) are based on Heidarzadeh and Satake (2014) and (2015), respectively. The maximum initial elevation and depression waves are marked in each panel

force, gravity and dissipation (Table 2). Therefore, we apply the following relationships for estimating the terminal velocity $\left(u_{t}\right)$, initial acceleration $\left(a_{0}\right)$ and motion of slide $\left(S_{t}\right)$ (Watts 2000):

$a_{0}=\frac{\left(m_{b}-m_{0}\right) g\left(\sin \theta-C_{n} \cos \theta\right)}{m_{b}+C_{m} m_{0}}$

$u_{t}=\sqrt{\frac{2\left(m_{b}-m_{0}\right) g\left(\sin \theta-C_{n} \cos \theta\right)}{C_{d} \rho_{0} w B \sin \theta}}$

Our approach is to fit an empirical equation to the data of the maximum negative initial amplitude of landslide-generated waves $\left(\eta_{\max , \mathrm{n}}\right)$. The dataset is partially from published physical experiments (i.e. Watts 1997; Enet and Grilli 2007; Najafi-Jilani and AtaieAshtiani 2008; Ataie-Ashtiani and Najafi-Jilani 2008) and partially from laboratory experiments conducted in this study as well as some field data from past landslide tsunamis.

We consider a submarine slide as a moving rigid body along a straight incline (Fig. 2b) with the centre of mass motion $\left(S_{t}\right)$ parallel to the incline and subject to external forces from added mass, drag

$$
S_{t}=S_{0}\left[\ln \cos \left(\frac{t}{t_{0}}\right)\right]
$$

where $m_{b}$ is the solid mass; $w$ is the width of the slide; $B$ is the length of the slide; $m_{0}$ is the displaced mass of water which can be obtained from the water density $\left(\rho_{0}\right)$ and the solid block volume $(V)$ through the following equation: $m_{0}=\rho_{0} V ; C_{m}$ is the added mass coefficient; $C_{n}$ is the Coulombic friction, which is influenced by the solid block and incline materials; $C_{d}$ is the drag 
Fig. 2 (a) Photo showing the wave flume, the two wave gauges (WG-1, WG-2), the slope and the sliding mass used in this study. (b) Sketch showing the landslide parameters. The thindashed line shows the rope used for holding and releasing the block. (c) A photo of the largest solid block

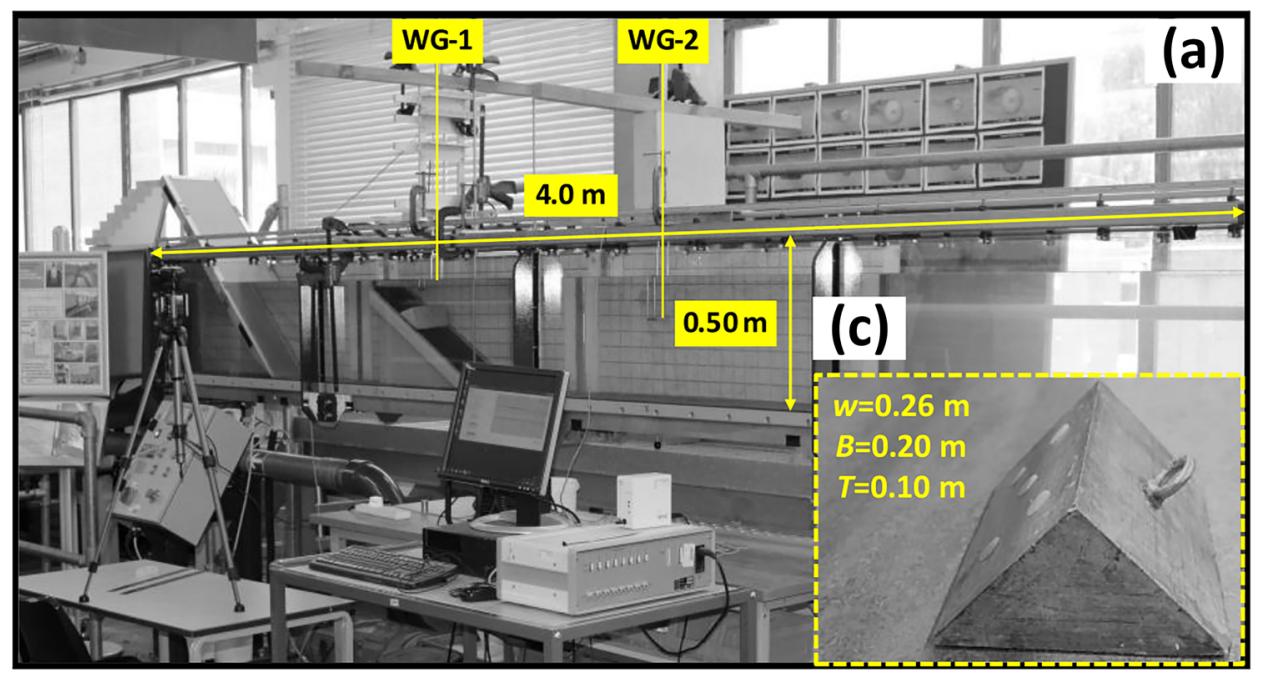

WG-1

WG-2

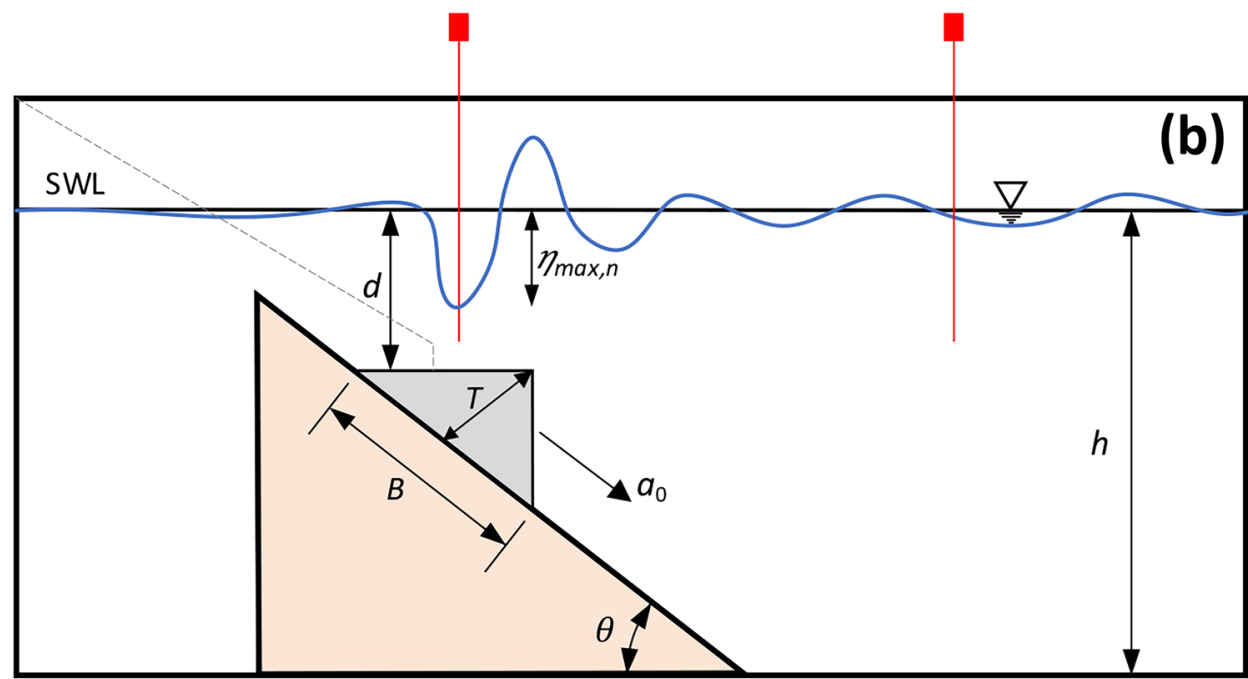

coefficient depending on the solid block shape; and $S_{t}$ is an approximation of centre of mass motion along the slope over time. The characteristic distance $\left(s_{0}\right)$ and characteristic time $\left(t_{0}\right)$ of landslide motion are derived directly from the equation of solid block motion (Eq. 3) as $s_{0}=\frac{u_{t}{ }^{2}}{a_{0}}$ and $t_{0}=\frac{u_{t}}{a_{0}}$.

Table 1 A few existing predictive equations for estimating the maximum initial wave amplitude of submarine landslides $\left(\eta_{\max }\right.$ or $\left.\eta_{\max , \mathrm{n}}\right)$

\begin{tabular}{|c|c|c|}
\hline Equation* & Range of validity & Author \\
\hline$\eta_{\max }=\frac{\tau t_{r}}{2 \rho C_{0}}$ & $X_{f}<x-B-C_{0}$ & \multirow{2}{*}{$\begin{array}{l}\text { Harbitz and Pedersen } \\
\text { (1992) }\end{array}$} \\
\hline$\eta_{\max }=\frac{\tau B}{2 \rho C_{0}{ }^{2}\left|1-F_{r}\right|}$ & $X_{f}>B$ & \\
\hline$\eta_{\max }=0.3945 \mathrm{~V}$ & N/A & Murty (2003) \\
\hline$\eta_{\max , \mathrm{n}}=S_{0}(0.05741-0.0431 \sin \theta)\left(\frac{T}{B}\right)\left(\frac{B \sin \theta}{d}\right)^{1.25}$ & $\begin{array}{l}\theta \in[5,30]^{\circ} \\
d / d_{\text {ref }} \in[0.06,3] \\
T / B \in[0.008,0.2]\end{array}$ & Watts et al. (2005) \\
\hline
\end{tabular}

${ }^{*} \eta_{\max }$ is the wave zero-to-trough (or zero to crest) amplitude; $\eta_{\max , n}$ is the wave zero-to-trough amplitude. For Murty (2003), the input value for $V$ must be in $10^{6} \mathrm{~m}^{3} ; \theta$ is the angle of the slope; $S_{0}$ is the characteristic distance of landslide motion; $d_{\text {ref }}=B \sin \theta$ is the reference thickness; $X_{f}$ is the shifted distance of two families of free waves; $t_{r}$ is the running time of slide; $F_{r}$ is the Froude number $\left(F_{r}=U / C_{0}\right.$; where $U$ is the slide velocity and $C_{0}=\sqrt{g h}$ is the water phase speed with $h$ as the water depth); $\tau$ the is shear stress; $C_{0}$ is the wave speed; $\gamma_{s}=\rho_{s} / \rho_{w}$ is the slide specific gravity; $\rho_{s}$ is the solid block density and $\rho_{w}$ is the water density. 


\section{Technical Notes}

Table 2 Characteristics of the three solid concrete blocks used for landslide experiments in this study

\begin{tabular}{|lccccccc}
\hline Solid block & $B(\mathrm{~m})$ & $w(\mathrm{~m})$ & $T(\mathrm{~m})$ & $V\left(\mathrm{~km}^{3}\right)$ & $m_{b}(\mathrm{~kg})$ & $m_{o}(\mathrm{~kg})$ & $\gamma_{s}$ \\
\hline Concrete triangular prism I & 0.200 & 0.260 & 0.100 & $2.600 \times 10^{-12}$ & 6.760 & 2.600 & 2.60 \\
\hline Concrete triangular prism II & \multirow{2}{*}{0.141} & 0.260 & 0.071 & $1.292 \times 10^{-12}$ & 3.355 & 1.292 & 2.60 \\
\hline Concrete triangular prism III & \multirow{2}{*}{0.106} & 0.260 & 0.053 & $0.730 \times 10^{-12}$ & 1.900 & 0.730 & 2.60 \\
\hline
\end{tabular}

${ }^{\star}$ Parameters are as follows: $B$, slide length $(\mathrm{m}) ; w$, slide width $(\mathrm{m}) ; T$, slide thickness $(\mathrm{m}) ; V$, slide volume $\left(\mathrm{km}^{3}\right) ; m_{b}$, solid block mass $(\mathrm{kg}) ; m_{0}$ the displaced mass of water $(\mathrm{kg})$ and $\gamma_{s}$, slide specific gravity
To determine the kinematic coefficients $\left(C_{n}, C_{d}, C_{m}\right)$, we used Eqs. (1) and (2). In particular, for determining the Coulombic friction coefficient $\left(C_{n}=\tan \psi\right)$, first, we measured the critical incline angle $(\psi)$ by increasing the slope angle in the laboratory until the block starts to slide. The test was repeated three times for each solid block, and the average value of $\psi$ was taken. Measurements of the terminal velocity $\left(u_{t}\right)$ and initial acceleration $\left(a_{0}\right)$ were done by using an accelerometer (model: 3-Axis Vibration/Acceleration Data Logger OM-VIB-101; https://www.omega.co.uk/). The results were then applied to Eqs. (1) and (2) in order to calculate $C_{d}$ and $C_{m}$. For every solid block, the measurements of velocity and acceleration were repeated three times, and the average values were taken. Based on the measurements, the mean drag coefficient of $C_{d} \cong 1.32$ and $C_{m} \cong 0.84$ were obtained.

The characteristic tsunami wavelength $\left(\lambda_{0}\right)$ is given by the following equation (Watts 1998; Grilli and Watts 2005):

$\lambda_{0}=t_{o} \sqrt{g d}$

where $g$ is the gravitational acceleration and $d$ is the initial submergence depth. To cope with the downscaling effect of real events into laboratory size, Froude similarity has been applied in this study. We note that Froude similarity may work best for situations where the friction effects are negligible. For submarine landslides, dispersive effects can be expressed by the relative depth parameter, $\mu=d / \lambda_{0}$ (Table 3 ). The values of $\mu$ higher than $\sim 0.5$ indicate fully dispersive deep-water waves, whereas a value of less than $\sim 0.05$ shows nondispersive long waves (Dean and Dalrymple 1991). The Froude number $\left(F_{r}\right)$ is a measure of the terminal landslide velocity $\left(u_{t}\right)$ relative to the speed of a shallow-water wave in water depth $(h)$. In general, for experimental studies of submarine slides, $F_{r}$ was defined with the maximum slide velocity reached during the submarine slide motion $\left(u_{t}\right)$ (Watts 1997):

$F_{r}=\frac{u_{t}}{\sqrt{g h}}$

Typical real-world submarine landslide-generated tsunamis are in the range of $F_{r}<1$ (McFall and Fritz 2016).

Figure 3 presents some of existing landslide laboratory data. The data are from Watts (1997) (abbreviated as WTS-97 hereafter), Enet and Grilli (2007) (ENT-07) and Najafi-Jilani and Ataie-Ashtiani (2008) (JIL-08). WTS-97 used only triangular prisms in their experiments whereas ENT-07 employed elliptic blocks. A range of geometrical shapes (square, triangle and circle) was used by JIL-o 8 to model submarine landslides. Due to the gaps in existing experimental data (Fig. 3), some complementary experiments were required to provide a satisfactory dataset for deriving our new predictive equation, which would help to fill the gap in data. While the distribution of data over submergence depth appears to be satisfactory (Fig. 3a), there are major data gaps for other parameters such as the slide volume (Fig. 3b) and slope angle (Fig. 3c). Although the data range for $\theta$ in existing literature varies from $15^{\circ}$ to $60^{\circ}$, it covers only four values of $15^{\circ}, 30^{\circ}, 45^{\circ}$ and $60^{\circ}$ with very limited data points for each angle. Accordingly, we focused on producing data for $V$ and $\theta$ by considering three different slide volumes (from $1 \times 10^{-12} \mathrm{~km}^{3}$ to $3 \times 10^{-12} \mathrm{~km}^{3}$ ) (Table 2) and five slope angles $\left(\theta=20^{\circ}, 30^{\circ}, 38^{\circ}, 45^{\circ}\right.$ and $\left.50^{\circ}\right)$. The three values for $V$ and three values for $\theta$ in our experiments are new as compared to existing data. Two values of $\theta$, however, have been available from past experiments; the reason for using these values of $\theta$ was to produce a range of values for $\theta$ enabling us to establish a relationship between $\theta$ and $\eta_{\max , \mathrm{n}}$. As seen in Fig. 3 , the existing data indicate an inverse correlation between $d$ and $\eta_{\max , \mathrm{n}}$ (Fig. 3a) and a direct relationship between $V$ and $\eta_{\max , \mathrm{n}}$ (Fig. 3b). The relationship between $V$ and $\eta_{\text {max,n }}$ can be seen by looking at a particular dataset (for example white-open circles) at a time (Fig. 3 b). Regarding $\theta$, our new experimental data (open circles in Fig. 3c) give a direct relationship between $\theta$ and $\eta_{\max , \mathrm{n}}$.

A series of physical tests were performed in a $0.26 \mathrm{~m}$ wide, $0.50 \mathrm{~m}$ deep and $4.0 \mathrm{~m}$ long wave tank at Brunel University London (UK). The experimental set-up included five different inclined planes (i.e. $20^{\circ}, 30^{\circ}, 38^{\circ}, 45^{\circ}$ and $50^{\circ}$ ). The solid blocks had three different volumes (Table $2 ; 2.600 \times 10^{-12} \mathrm{~km}^{3}, 1.292 \times$ $10^{-12} \mathrm{~km}^{3}$ and $0.7303 \times 10^{-12} \mathrm{~km}^{3}$ ). Other specifications of the solid blocks are given in Table 2. We used a hook on the solid block and a rope to move the solid block in position prior to release. The initial submergence $(d)$ and water depth $(h)$ in the tank were adjusted to constant values of $d=0.08 \pm 0.005 \mathrm{~m}$ and $h=0.375 \mathrm{~m}$ as we aimed at producing more laboratory data for the set-up previously used by Watts (1997). Overall, we conducted 15 physical experiments by varying slope angles and slide volumes (Table 2) whose resulting waveforms are shown in Figs. 4 and 5.

The generated surface waves were measured using two precision capacitance wave gauges (twin wire wave probe; HRIA-1016: http://equipit.hrwallingford.com/): one located at the top of the submerged slides and the other at a distance of $1.6 \mathrm{~m}$ from the first gauge (Fig. 2a). Only the gauge located on the top of the mass is used in the present study. The gauge recordings were collected through an acquisition system at $50 \mathrm{~Hz}$ with an accuracy of $\pm 0.1 \mathrm{~mm}$. The waveforms resulted from our experiments are sorted into five groups based on the slope angles (Figs. 4 and 5). Figures 4 and 5 demonstrate that by increasing the slope angle $(\theta)$ and slide volume $(V)$, the maximum initial amplitude $\left(\eta_{\max , \mathrm{n}}\right)$ increases. Increasing the initial submergence depth $(d)$ causes a decrease in 

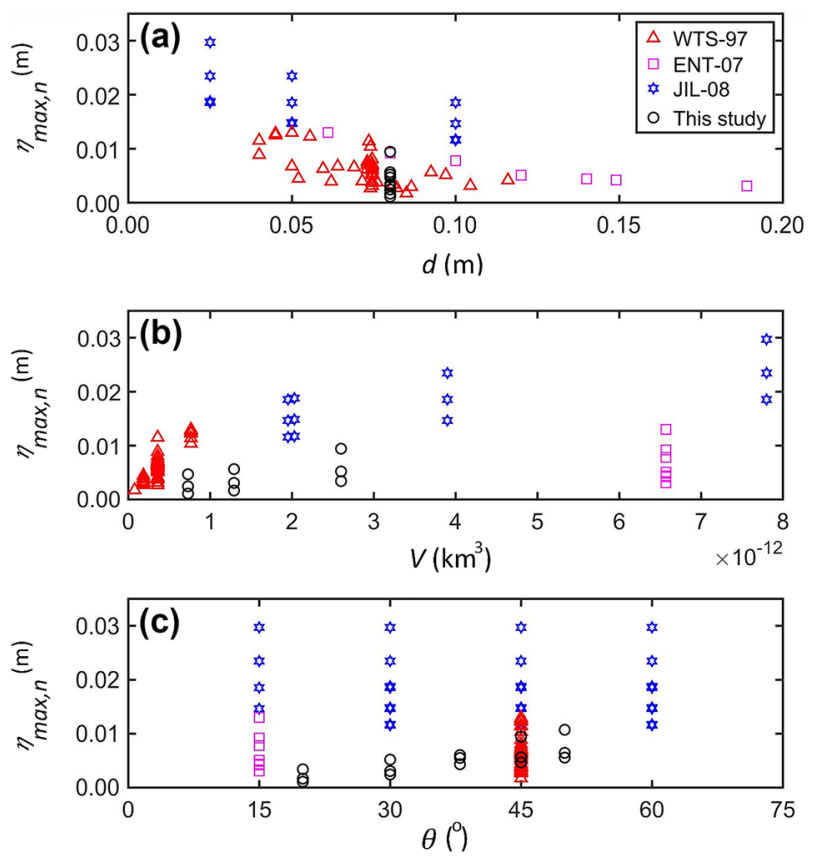

Fig. 3 Existing experimental data on submarine landslide-generated waves. Experimental data relating the maximum initial wave amplitude $(\theta=)$ with (a) the initial submergence depth, $V$; (b) the volume of the sliding mass, $\theta$; and (c) the angle of the slope $(\theta)$. Abbreviations: WTS-97, Watts (1997); ENT-07, Enet and Grilli (2007); JIL-08, Najafi-Jilani and Ataie-Ashtiani (2008)

$\eta_{\text {max, } \mathrm{n}}$. Therefore, the highest $\eta_{\text {max, } \mathrm{n}}$ is generated by the largest concrete prism over the $50^{\circ}$ slope (Fig. $4 \mathrm{a}$, red).

Based on Sabeti and Heidarzadeh (2020), the slide volume ( $V$, initial submergence depth $(d)$ and slope angle $(\theta)$ are among the most important parameters for predicting the initial wave amplitude. Hence, we define the non-dimensional maximum initial tsunami amplitude $\left(\frac{\eta_{\max , n}}{d}\right)$ as a function of nondimensional forms of these most important parameters $\left(\sin \theta ; \frac{V}{d^{3}} ; \frac{V}{B d^{2}} ; \frac{d}{B} ; \frac{d}{h}\right.$ and $\left.\frac{m_{b}}{\rho_{w} B d^{2}}\right)$ as previously adapted by Watts (1997), Watts et al. (2005) and Najafi-Jilani and Ataie-Ashtiani (2008). We developed and examined 14 empirical equations using the aforementioned non-dimensional parameters. These nondimensional forms have been inspired by previous research including Fritz et al. (2004), Heller and Spinneken (2015) and Slingerland and Voight (1982). The powers and coefficients of the empirical equations are obtained using curve fitting of the experimental data applying the polynomial fitting toolbox of the MATLAB software (MathWorks 2020). However, the final predictive equation for estimating $\times$ are achieved through the stochastic optimization technique of genetic algorithm (GA) (MathWorks 2020). The GA toolbox uses a cost function to build a set of versatile routines for implementing a wide range of GA methods (Chipperfield et al. 1994). To quantify the quality of fit between observations (i.e. experimental and field data) and the calculations from the predictive equations, we used the normalized root mean square error (NRMSE) equation (Aida 1978; Heidarzadeh et al., 2016): 
$N R M S E=\frac{\sqrt{\sum_{i=1}^{N}\left(o b s_{i}-c a l_{i}\right)^{2}}}{\sqrt{\sum_{i=1}^{N}\left(o b s_{i}-\overline{o b s}\right)^{2}}}$

where $i=1,2, \ldots, N$ refers to the number of observations/calculations; obs stands for observations (experimental/field data); cal is calculated values from predictive equations; and $\overline{o b s}$ is the average of observations. In an ideal case, if the agreement between observations and calculations is perfect, the NRMSE becomes zero.
Analysing the effects of individual landslide parameters

In this section, we use the experimental data to establish a relationship between $\eta_{\text {max,n }}$ and different landslide parameters, based on dimensional parameters.

To determine the power of the relationship between $d$ and $\eta_{\max , \mathrm{n}}$, we fitted three curves to the experimental data of WTS-97, ENT-07 and JIL-08 (Fig. 6a). The initial submergence depth varies in the range of $0.025-0.189 \mathrm{~m}$ for these experimental data. We observed an inverse relationship between $d$ and $\eta_{\max , \mathrm{n}}$; however, the rate of
Fig. 4 Recordings of the landslide-generated waves at WG-1 (see Fig. 2 for its location) in laboratory experiments for cases of slopes $\theta=38^{\circ}, 45^{\circ}$ and $50^{\circ}$. The parameters for each experiment are shown as legends in the panels. (a) For slope angle 50 degrees. (b) For slope angle 45 degrees. (c) For slope angle 38 degrees
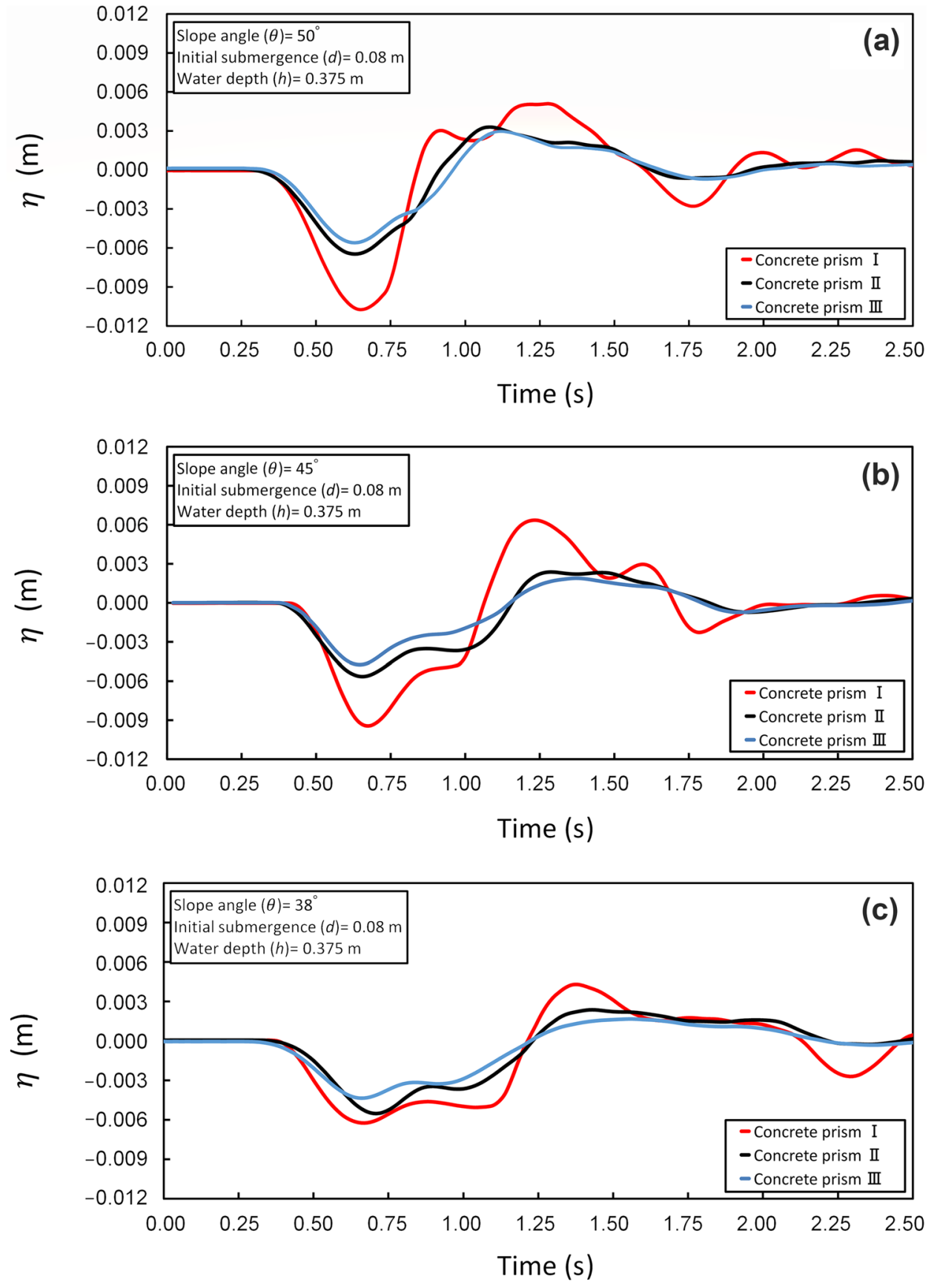
Fig. 5 Recordings of the landslide-generated waves at WG-1 (see Fig. 2 for its location) in laboratory experiments for cases of slopes $\theta=20^{\circ}$ and $30^{\circ}$. The parameters for each experiment are shown as legends in the panels. (a) For slope angle 30 degrees. (b) For slope angle 20 degrees
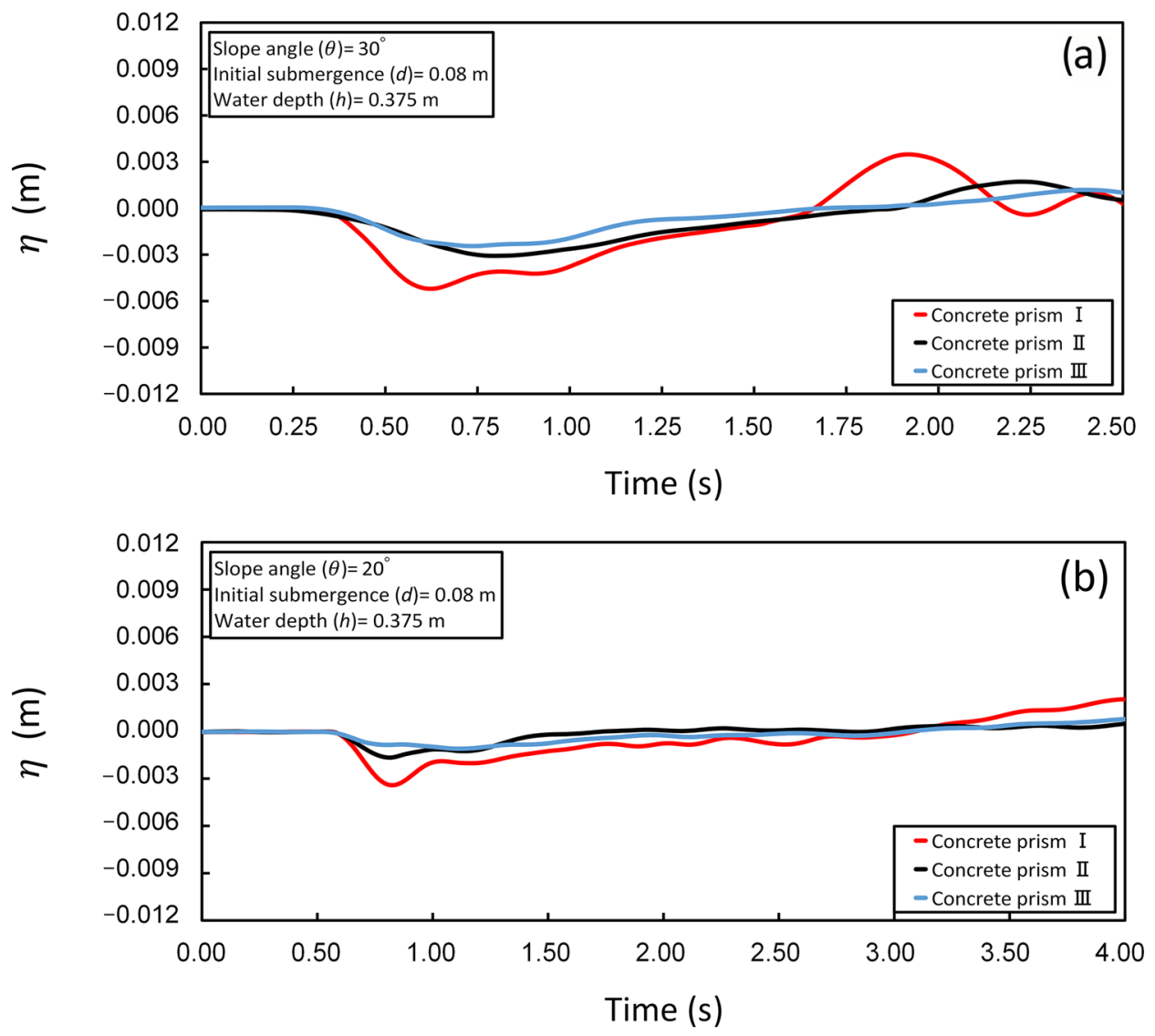

change was different for various experimental data (Fig. 6a). The powers of the relationship obtained for the experimental data of WTS-97 and JIL-08 were in a similar range whereas that of ENTo7 was different. This could be attributed to the different landslide geometry used by ENT-07 and its 3D nature (Heller and Hager 2011; Ruffini et al. 2019). Our experimental set up is similar to the data of JIL-08 and WTS-97. Accordingly, we consider the effects of the initial submergence, $d$, with the average relationship power of WTS97 and JIL-08 data as follows:

$\eta_{\max , \mathrm{n}} \propto d^{-1.095}$

For $V$, we used the existing experimental data of WTS-97 and JIL-08 along with our own physical tests (Fig. 6b). These data, with $V$ in the range of $0.35 \times 10^{-12}-7.80 \times 10^{-12} \mathrm{~km}^{3}$, indicated a direct relationship between $V$ and $\eta_{\max , n}$. The solid lines and the equations associated with them (Fig. 6b) were considered for deriving the relationship. The average powers obtained through fitting equations to the experimental data of JIL-o8, and this study were employed to provide the power of $V$ as follows:

$\eta_{\text {max, } \mathrm{n}} \propto V^{0.295}$

The direct relationship between $\eta_{\max , \mathrm{n}}$ and $\theta$ was demonstrated through our physical experiments and that of JIL-08 (Fig. 7). The effect of $\theta$ was examined by changing the slope angle in the range of $15-60^{\circ}$. We obtained the power of $\sin \theta$ by calculating the average of the powers of the fitted equations using experimental data of this study and JIL-08 as follows:

$\eta_{\max , \mathrm{n}} \propto(\sin \theta)^{1.650}$

\section{The new predictive equation}

The curve fitting on the existing experimental data indicates that $V$ and $\theta$ are directly related to $\eta_{\max , n}$ (Figs. $6 \mathrm{~b}$ and 7) while $\eta_{\max , \mathrm{n}}$ is inversely correlated (Fig. 6a). By considering the non-dimensional forms of these three essential landslide parameters, here, 14 equations are developed for predicting $\eta_{\text {max,n }}$ (Eqs. 10-23 in Table 4). Equations (10), (13), (16) and (19) are inspired by equations for individual parameters in the "Analysing the effects of individual landslide parameters" section while the structures of Eqs. (11), (14), (17) and (20) are encouraged by Sabeti and Heidarzadeh (2020). For Eqs. (12), (15), (18) and (21), we followed the format of a previous equation by Murty (2003); and finally, the two Eqs. (22) and (23) are inspired by Heller and Spinneken (2015). For deriving these equations, we have applied three sets of available experimental data (Watts 1998; Enet and Grilli 2007; NajafiJilani and Ataie-Ashtiani 2008), the present experimental data (Figs. 4 and 5), and some field data from past landslide tsunami events (Table 5). These 14 equations are compared based on 
Fig. 6 Curve fitting on the experimental data of the maximum initial wave amplitude (d) versus (a) initial submergence depth, $\eta_{\max , \mathrm{n} \text {, and (b) }}$ volume of the sliding mass, $\eta_{\text {max,n. Abbreviations: WTS-97, }}$ Watts (1997); ENT-07, Enet and Grilli (2007); JIL-08, Najafi-Jilani and Ataie-Ashtiani (2008). The solid red circles show the data points obtained through the experimental works of this study
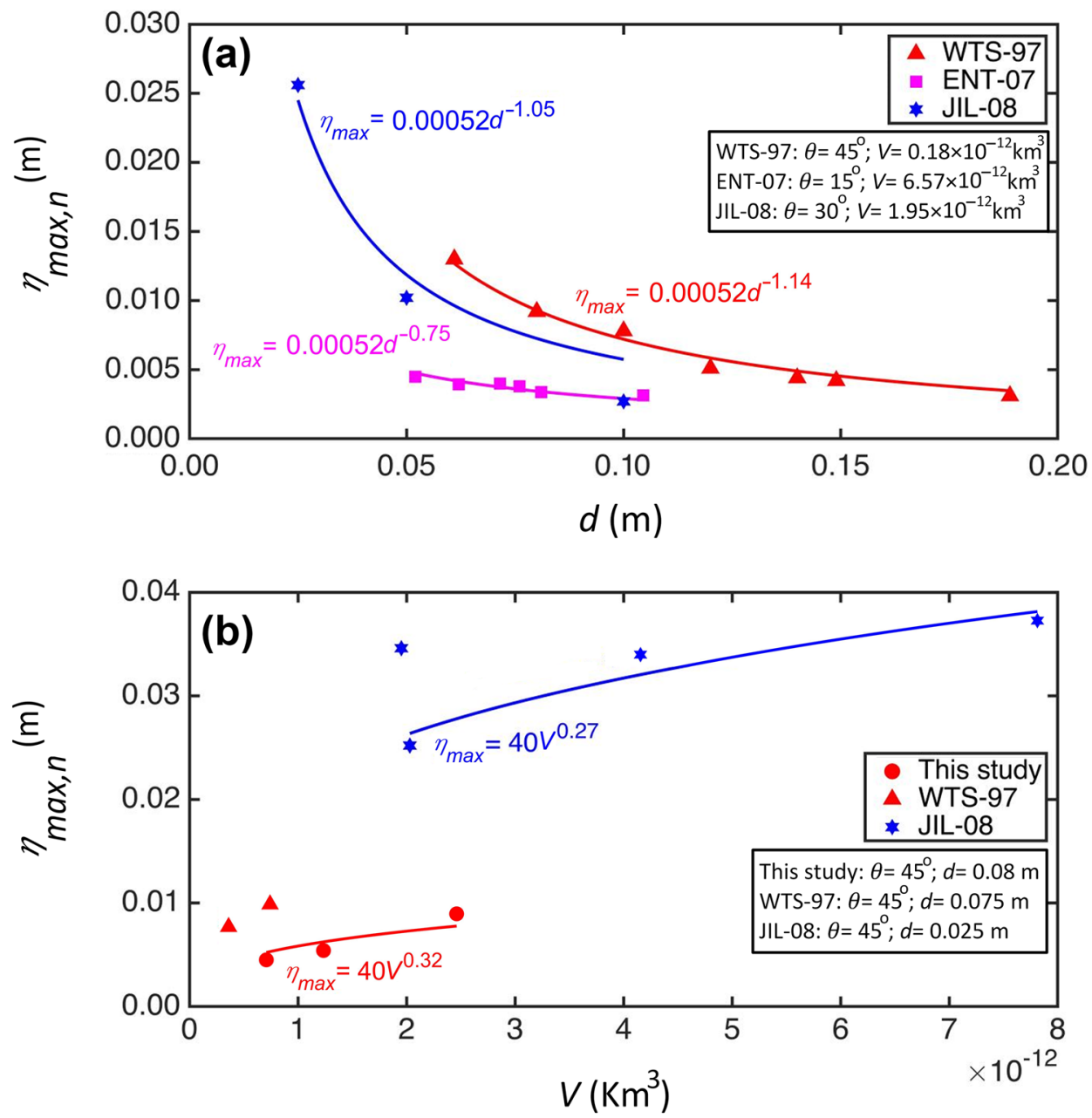

the NRMSE index (Eq. 6). Among the nominated equations in Table 4, Eq. (19) gives the minimum NRMSE indicating a better agreement between calculations and observations (Table 4, last column). The performance of the derived equations (Eqs. 10-23) is shown by comparing the calculated maximum negative initial wave amplitude using various equations $\left(\eta_{\max , n_{\text {_cal }}}\right)$ and the observed experimental and field data $\left(\eta_{\max , n_{\text {_obs }}}\right)$ (Fig. 8$)$. Equation (19) is able to predict $\eta_{\max }$ with acceptable accuracy (i.e. $N R M S E<0.2$ ) for both experimental and field data (Fig. 8).

In order to further evaluate the performance of Eq. (19), it is applied to three past landslide tsunami events whose data were not used for developing this equation (Table 6; the events of 2018 Palu, 2013 Pakistan and 1998 PNG). The observed values (Table 6; column 7) are the initial wave amplitudes on the top of the landslide locations (Fig. 2) which were numerically estimated by Synolakis et al. (2002) and Heidarzadeh and Satake
(2017) for the PNG and Pakistan events, respectively. For the 2018 Palu event, the estimation of the maximum initial wave is based on the bathymetric survey of Frederik et al. (2019) and applying empirical equations of Watts et al. (2005). The results in Table 6 indicate a relatively good agreement between the calculated values using Eq. (19) and the observed data. The average prediction errors, based on percentage of deviations between observations and predictions, are 70\%, 20\% and $24 \%$ for the 1998, 2013 and 2018 events, respectively, indicating that the observations and calculations are in the same range for the 2013 and 2018 events while the equation slightly overestimates for the 1998 event. Prior to this study, the estimates from existing equations for $\eta_{\max , n}$ were divided by a few orders of magnitudes (factors of thousands) from actual observation data (Sabeti and Heidarzadeh 2020). Although predictions by Eq. (19) are associated with some errors, it is a step forward in 
Fig. 7 Curve fitting on the experimental data of the maximum initial wave amplitude $\left(\eta_{\text {max }, \mathrm{n}}\right)$ and slope angle $(\theta)$. JIL-08 is the acronym for Najafi-Jilani and AtaieAshtiani (2008). Panel (a) is for the experimental data of JIL-08 while panel (b) is for our experimental work
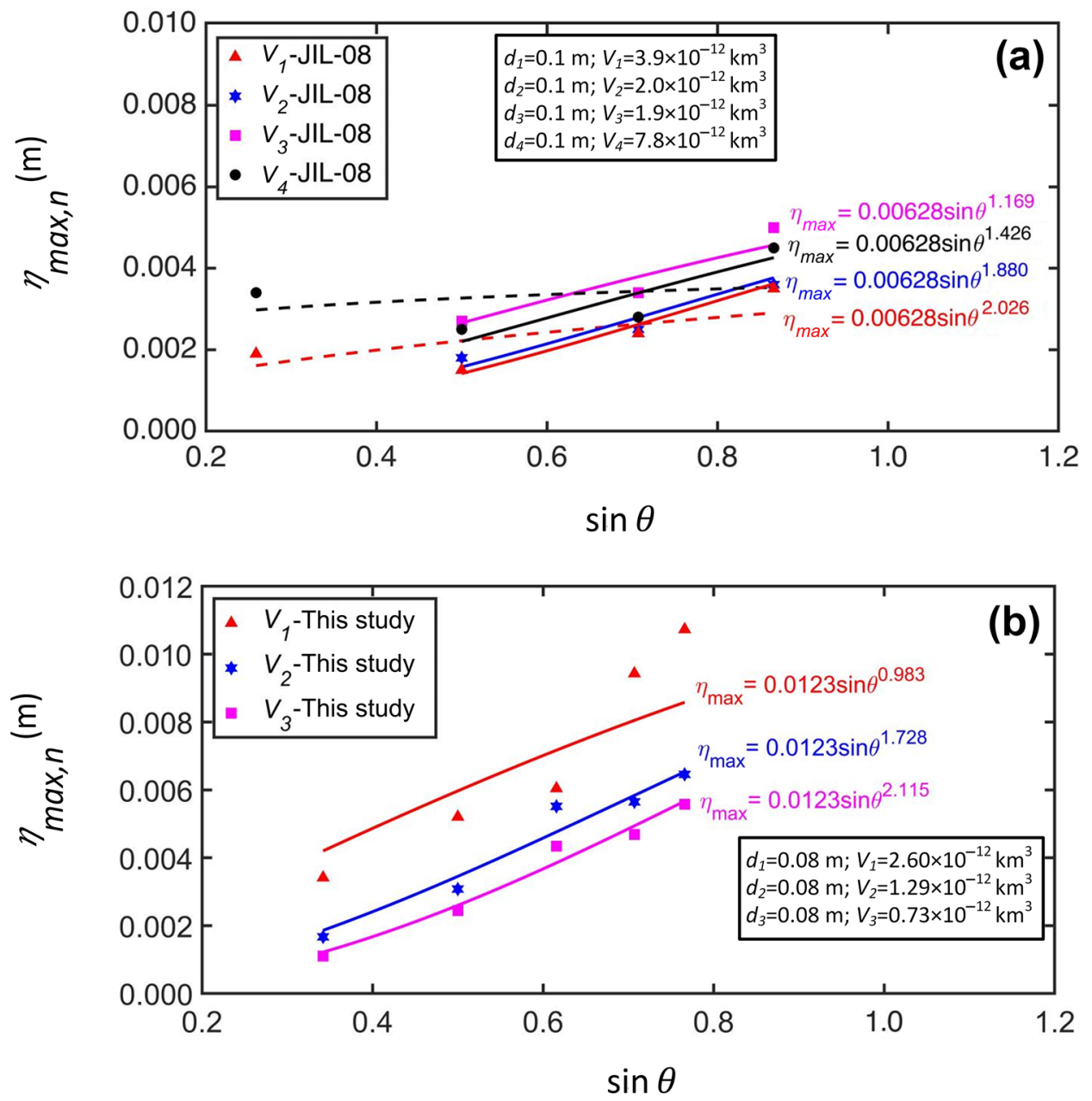

estimating the maximum amplitudes of the landslide generated waves. This improvement could be attributed to our use of both experimental and field data while deriving the new predictive equations.

A challenge for landslide tsunami hazard assessment is often the lack of credible information on different landslide parameters. Although high-quality numerical models are available, they are not useful without detailed information about the location, geometry and rheology of the landslides. In this context, empirical equations, such as Eq. (19), can be helpful for preliminary hazard investigations. In particular, at the early stages of landslide tsunami hazard studies, empirical equations can help to provide valuable information for future detailed numerical modelling. The new predictive equation (Eq. 19) is capable of supplying a rapid and fair estimate of potential hazard associated with submarine landslides given the limited information available about submarine landslides. 


\section{Technical Notes}

Table.4 The candidate non-dimensional equations used in this study for estimating the maximum initial amplitude of landslide waves $\left(\eta_{\text {max, }}\right)$ Candidate equations

Equation NRMSE number

$\frac{\eta_{\max , \mathrm{n}}}{\boldsymbol{d}}=0.023 \times \frac{\left(\frac{v}{d^{3}}\right)^{0.295} \times \sin 1^{1.650}}{\left(\frac{d}{B}\right)^{1.095}}$

$\frac{\eta_{\max , \mathrm{n}}}{d}=0.068 \times\left(\frac{\frac{v}{d^{3}} \cdot \sin \theta}{\frac{d}{B}}\right)^{0.33}$

$\frac{\eta_{\max , \mathrm{n}}}{d}=0.049 \times\left(\frac{\frac{v}{d^{3}} \cdot \sin \theta}{\frac{d}{B}}\right)$

$\frac{\eta_{\max , \mathrm{n}}}{\boldsymbol{d}}=0.0080 \times \frac{\left(\frac{v}{d^{3}}\right)^{0.295} \times \sin \theta^{1.650}}{\left(\frac{d}{h}\right)^{1.095}}$

$\eta_{\operatorname{max.n}}=0.032 \times\left(\frac{\frac{v}{d^{3}} \cdot \sin \theta}{\frac{0.39}{h}}\right)^{0.39}$

$d=0.032 \times\left(\frac{\frac{d}{b}}{\frac{d}{h}}\right)$

$\frac{\eta_{\operatorname{max,n}}}{d}=0.0024 \times\left(\frac{\frac{v}{d^{3}} \cdot \sin \theta}{\frac{d}{h}}\right)$

$\frac{\eta_{\max , \mathrm{n}}}{d}=0.014 \times \frac{\left(\frac{v}{B d^{2}}\right)^{0.295} \times \sin \theta^{1.650}}{\left(\frac{d}{h}\right)^{1.095}}$

$\frac{\eta_{\max , \mathrm{n}}}{d}=0.06 \times\left(\frac{\frac{v}{B d^{2}} \cdot \sin \theta}{\frac{d}{h}}\right)$

$\frac{\eta_{\max , \mathrm{n}}}{d}=0.016 \times\left(\frac{\frac{v}{d^{3}} \cdot \sin \theta}{\frac{d}{B}}\right)$

$\frac{\eta_{\max , \mathrm{n}}}{d}=0.048 \times \frac{\left(\frac{v}{B d^{2}}\right)^{0.295} \times \sin \theta^{1.650}}{\left(\frac{d}{B}\right)^{1.095}}$

$\frac{\eta_{\operatorname{max,n}}}{d}=0.027 \times\left(\frac{\frac{v}{B d^{2}} \cdot \sin \theta}{\frac{d}{B}}\right)$

$\frac{\eta_{\max , \mathrm{n}}}{d}=0.066 \times\left(\frac{\frac{v}{B d^{2}} \sin \theta}{\frac{d}{B}}\right)$

$\frac{\eta_{\operatorname{max,n}}}{d}=0.037 \times \frac{\left(\frac{m_{b}}{\rho_{w} B d^{2}}\right)^{0.295} \times \sin \theta^{1.650}}{\left(\frac{d}{B}\right)^{1.095}}$

*Based on Eq. (6) 
Fig. 8 Comparison of experimental and field data $\left(\eta_{\text {max,n_obs }}\right)$ with estimates made by various predictive equations $\left(\eta_{\text {max,n }}\right.$ cal $)$ (see Table 4 for Eqs. 10-23). Panel (a) is for Equations 10-16 and panel (b) is for Equations 17-23
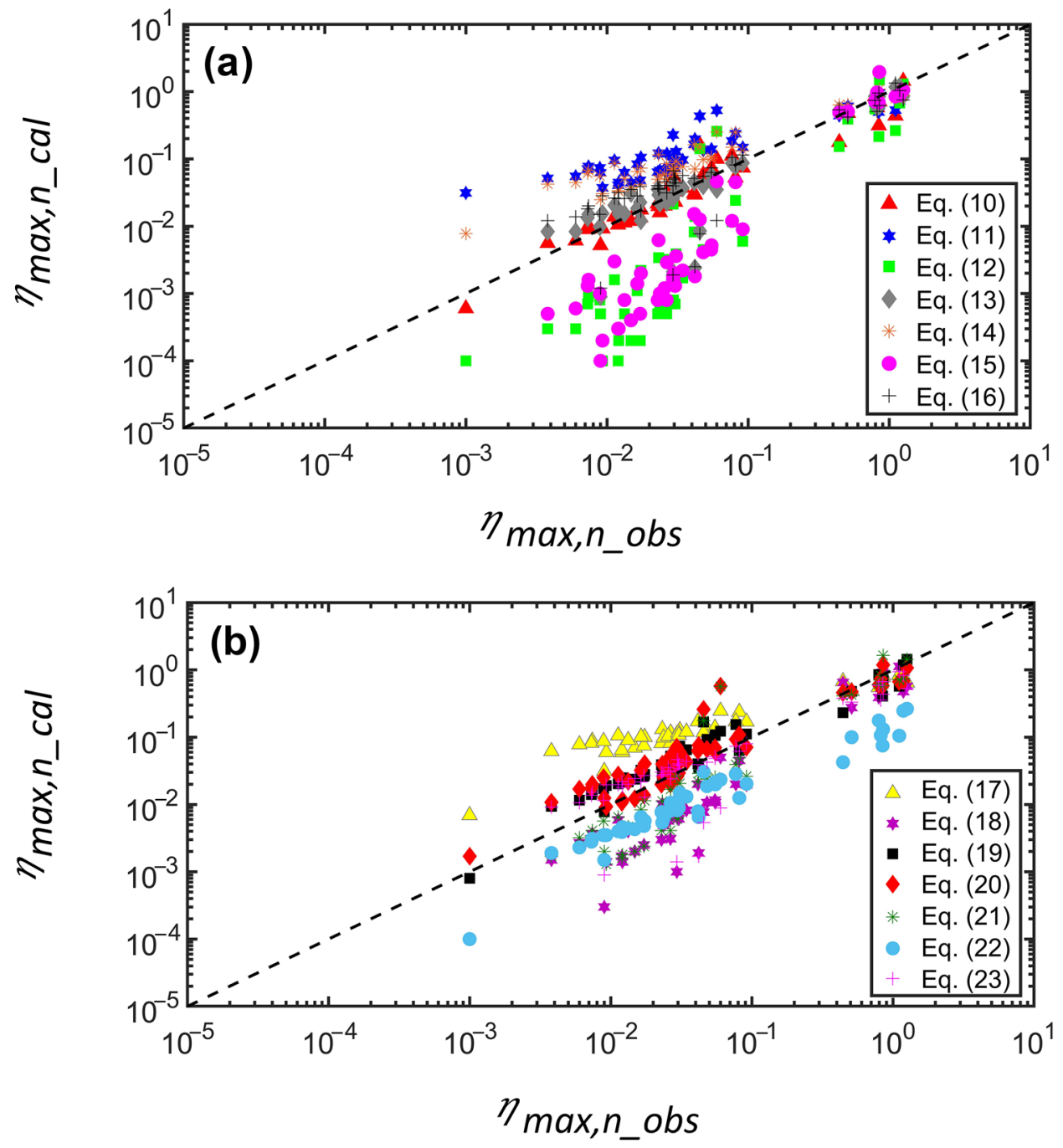

Table 5 Field data of actual landslide tsunami events used in this study to extract the predictive equations

\begin{tabular}{|c|c|c|c|c|c|c|c|}
\hline Event name & $\begin{array}{l}\text { Slide } \\
\text { volume } \\
\left(\mathrm{km}^{3}\right)\end{array}$ & $\begin{array}{l}\text { Initial } \\
\text { submergence } \\
\text { depth }(\mathrm{m})\end{array}$ & $\begin{array}{l}\text { Water depth } \\
(\mathrm{m})\end{array}$ & $\begin{array}{l}\text { Slide length } \\
\text { (m) }\end{array}$ & Slope angle $\left(^{\circ}\right)$ & $\begin{array}{l}\text { Maximum } \\
\text { observed initial } \\
\text { amplitude (m) }\end{array}$ & References \\
\hline 1975 Kitimat (Canada) & 0.023 & $80-120$ & $160-180$ & $274-1000$ & 11 & 4.2 & Murty (1979); Kirby et al. (2015) \\
\hline 1979 Nice (France) & 0.0022 & 47 & $50-100$ & $346-652$ & 11 & 1.4 & $\begin{array}{l}\text { Murty (2003); Dan et al. (2007); } \\
\text { loualalen et al. (2010) }\end{array}$ \\
\hline 1994 Skagway (USA) & 0.0032 & $26-40$ & $55-72$ & $180-600$ & 17.5 & 1.5 & $\begin{array}{l}\text { Watts et al. (2003); Rabinovich et al. } \\
\text { (1999) }\end{array}$ \\
\hline 1999 Izmit (Turkey) & 0.0052 & 25 & 55 & $140-160$ & 15 & 1.5 & Tinti et al. (2006) \\
\hline
\end{tabular}




\section{Technical Notes}

Table 6 Application of our final predictive equation (Eq. 19) to three worldwide landslide events whose data were not used for extracting Eq. (19)

\begin{tabular}{|c|c|c|c|c|c|c|c|c|}
\hline Event name & $\begin{array}{l}\text { Slide } \\
\text { volume } \\
\left(\mathrm{km}^{3}\right)\end{array}$ & $\begin{array}{l}\text { Initial submer- } \\
\text { gence depth } \\
\text { (m) }\end{array}$ & Slope angle $\left({ }^{\circ}\right)$ & Water depth (m) & $\begin{array}{l}\text { Slide length } \\
\text { (m) }\end{array}$ & $\eta_{o b s}(\mathrm{~m})$ & $\begin{array}{l}\eta_{c a l}(\mathbf{m}) \\
\text { using } \\
\text { Eq. (19) }\end{array}$ & References \\
\hline 2018 Palu & 0.09 & 800 & $10-16$ & 850 & 1500 & 9.7 & 7.4 & $\begin{array}{l}\text { Frederik et al. } \\
\text { (2019); Watts } \\
\text { et al. (2005) }\end{array}$ \\
\hline $\begin{array}{l}2013 \\
\text { Makran } \\
\text { (Pakistan) }\end{array}$ & $2.2-3.0$ & $1500-2000$ & 2 & $2500-3000$ & $10,000-15,000$ & $1.5-2.0$ & $1.0-1.8$ & $\begin{array}{r}\text { Heidarzadeh \& } \\
\text { Satake (2017) }\end{array}$ \\
\hline 1998 PNG & $4.0-7.0$ & $1000-2000$ & $5-15$ & $2000-3000$ & $3000-7000$ & $11-16$ & $2.0-44.3$ & $\begin{array}{l}\text { Tappin et al. } \\
\text { (2008); Synolakis } \\
\text { et al. (2002) }\end{array}$ \\
\hline
\end{tabular}

\section{Conclusions}

In this study, we developed a new predictive equation for the maximum negative initial wave amplitude $\left(\eta_{\max , n}\right)$ generated by submarine solid-block landslide tsunamis. This study was motivated by the fact that results from existing equations for $a$ were divided by a few orders of magnitudes from observation data. Here, we used existing experimental and field data and applied the genetic algorithm to develop a new predictive equation. Due to a gap in existing experimental data and lack of sufficient data on the relationship between initial landslide tsunami amplitude and landslide parameters, we generated some data points through laboratory experiments. We used the non-dimensional forms of three main landslide parameters for the new equation: initial submergence depth, landslide volumes and slope angle. Fourteen candidate equations with different formats were developed in this study, and their performances in reproducing experimental and field data were examined. Finally, the best equation was chosen based on the criterion of minimum Normalized Root Mean Square Error between observations and calculations. The proposed equation is capable of reproducing both experimental and field data with satisfactory accuracy.

\section{Acknowledgements}

The GMT software (Wessel and Smith 1998) is used for drafting some figures. We acknowledge the support from lab technicians at the Brunel University London for their assistance during the physical experiments. We are sincerely grateful to two anonymous reviewers and the Editor for their constructive review comments, which greatly helped to improve the manuscript.

\section{Funding}

MH is funded by the Royal Society, UK, grant number CHLIR1 $\mid 180173$.

\section{Declarations}

Conflict of interest The authors declare no competing interests.

Open Access This article is licensed under a Creative Commons Attribution 4.0 International License, which permits use, sharing, adaptation, distribution and reproduction in any medium or format, as long as you give appropriate credit to the original author(s) and the source, provide a link to the Creative Commons licence, and indicate if changes were made. The images or other third party material in this article are included in the article's Creative Commons licence, unless indicated otherwise in a credit line to the material. If material is not included in the article's Creative Commons licence and your intended use is not permitted by statutory regulation or exceeds the permitted use, you will need to obtain permission directly from the copyright holder. To view a copy of this licence, visit http://creativecommons. org/licenses/by/4.0/.

\section{References}

Aida I (1978) Reliability of a tsunami source model derived from fault parameters. J Phys Earth 26:57-73

Ataie-Ashtiani B, Najafi-Jilani A (2008) Laboratory investigations on impulsive waves caused by underwater landslide. Coast Eng 55(12):989-1004

Chipperfield AJ, Fleming PJ, Pohlheim H, Fonseca CM (1994) A genetic algorithm toolbox for MATLAB Proc. International Conference on Systems Engineering, Coventry, UK Vol. 6, No. 8

Dan G, Sultan N, Savoye B (2007) The 1979 Nice harbour catastrophe revisited: trigger mechanism inferred from geotechnical measurements and numerical modelling. Mar Geol 245(1):40-64

Dean RG, Dalrymple RA (1991) Water wave mechanics for engineers and scientists. World Scientific Publishing Company. 368 pages

Enet F, Grilli ST (2007) Experimental study of tsunami generation by three-dimensional rigid underwater landslides. J Waterw Port Coast Ocean Eng 133(6):442-454

Frederik MC, Adhitama R, Hananto ND, Sahabuddin S, Irfan M, Moefti O, Putra DB, Riyalda BF (2019) First results of a bathymetric survey of Palu Bay, Central Sulawesi, Indonesia following the tsunamigenic earthquake of 28 September 2018. Pure Appl Geophys 176(8):3277-3290

Fritz HM, Hager WH, Minor H-E (2004) Near field characteristics of landslide generated impulse waves. J Waterw Port Coast Ocean Eng 130(6):287-302

Fernández-Nieto ED, Bouchut F, Bresch D, Diaz MC, Mangeney A (2008) A new Savage-Hutter type model for submarine avalanches and generated tsunami. J Comput Phys 227(16):7720-7754

Gómez J, Berezowsky M, Lara A, González E (2016) Prediction of the water waves generated by a potential semisubmerged landslide in La Yesca reservoir. Mexico Landslides 13(6):1509-1518

Grilli ST, Watts P (2005) Tsunami generation by submarine mass failure. I: Modelling, experimental validation, and sensitivity analyses. J Waterw Port Coast Ocean Eng 131(6):283-297

Grilli ST, Tappin DR, Carey S, Watt SF, Ward SN, Grilli AR, Engwell SL, Zhang C, Kirby JT, Schambach L, Muin M (2019) Modelling of the 
tsunami from the December 22, 2018 lateral collapse of Anak Krakatau volcano in the Sunda Straits. Indonesia Sci Rep 9(1):1-3

Gusman AR, Supendi $P$, Nugraha AD, Power W, Latief $H$, Sunendar $H$, Widiyantoro S, Wiyono SH, Hakim A, Muhari A, Wang X (2019) Source model for the tsunami inside Palu Bay following the 2018 Palu earthquake. Indonesia Geophys Res Lett 46(15):8721-8730

Harbitz CB, Pedersen G (1992) Model theory and analytical solutions for large water waves due to landslides. Preprint series. Mech Appl Math NBN 23418

Heidarzadeh M, Ishibe T, Sandanbata O, Muhari A, Wijanarto AB (2020) Numerical modeling of the subaerial landslide source of the 22 December 2018 Anak Krakatoa volcanic tsunami, Indonesia. Ocean Eng 195:106733

Heidarzadeh M, Murotani S, Satake K, Ishibe T, Gusman AR (2016) Source model of the 16 September 2015 Illapel, Chile Mw 8.4 earthquake based on teleseismic and tsunami data. Geophys Res Lett 43(2):643-650

Heidarzadeh M, Satake K (2015) Source properties of the 17 July 1998 Papua New Guinea tsunami based on tide gauge records. Geophys J Int 202(1):361-369

Heidarzadeh M, Satake K (2017) A combined earthquake-landslide source model for the tsunami from the 27 November $1945 \mathrm{Mw} 8.1$ Makran Earthquake. Bull Seismol Soc Am 107(2):1033-1040

Heidarzadeh M, Satake K (2014) Possible sources of the tsunami observed in the northwestern Indian Ocean following the 2013 September 24 Mw 7.7 Pakistan inland earthquake. Geophys J Int 199(2):752-766

Heinrich P (1992) Nonlinear water waves generated by submarine and aerial landslides. J Waterw Port Coast Ocean Eng 118(3):249-266

Heller V, Spinneken J (2015) On the effect of the water body geometry on landslide-tsunamis: physical insight from laboratory tests and 2D to 3D wave parameter transformation. Coast Eng 104:113-134

Heller V, Hager WH (2011) Wave types of landslide generated impulse waves. Ocean Eng 38(4):630-640

Ioualalen M, Migeon S, Sardoux O (2010) Landslide tsunami vulnerability in the Ligurian Sea: case study of the 1979 October 16 Nice international airport submarine landslide and of identified geological mass failures. Geophys J Int 181(2):724-740

Iwasaki SI (1982) Experimental study of a tsunami generated by a horizontal motion of a sloping bottom. Bull Earthquake Res Ins 57:239-262

Kirby JT, Shi F, Nicolsky D, Ma G, Misra S, Rao P (2015) The 1975 Kitimat Landslide Tsunami: validation and comparative testing of modeling strategies. In: Coastal structures and solutions to coastal disasters, Eds: Wallendorf L, Cox DT, September 9-11, Boston, Massachusetts USA

Liu PF, Wu TR, Raichlen F, Synolakis CE, Borrero JC (2005) Runup and rundown generated by three-dimensional sliding masses. J Fluid Mech 536:107-144

Løvholt F, Glimsdal S, Harbitz CB (2020) On the landslide tsunami uncertainty and hazard. Landslides 17:2301-2315

Mathworks, (2020) MATLAB user manual. The Math Works Inc., MA, USA, p 282

McFall BC, Fritz HM (2016) Physical modelling of tsunamis generated by three-dimensional deformable granular landslides on planar and conical island slopes. Proc R Soc Lon A 472(2188):20160052

Murty TS (1979) Submarine slide-generated water waves in Kitimat Inlet. British Columbia J Geophys Res 84(C12):7777-7779

Murty TS (2003) Tsunami wave height dependence on landslide volume. Pure Appl Geophys 160(10-11):2147-2153

Najafi-Jilani A, Ataie-Ashtiani B (2008) Estimation of near-field characteristics of tsunami generation by submarine landslide. Ocean Eng 35(5-6):545-557
Rabinovich A, Thomson R, Kulikov E, Bornhold B, Fine IV (1999) The landslidegenerated tsunami of November 3, 1994, in Skagway Harbor, Alaska: a case study. Geophys Res Lett 26(19):3009-3012

Ruffini G, Heller V, Briganti R (2019) Numerical modelling of landslidetsunami propagation in a wide range of idealised water body geometries. Coastal Eng 153:103518

Sabeti R, Heidarzadeh M (2020) Semi-empirical predictive equations for the initial amplitude of submarine landslide-generated waves: applications to 1994 Skagway and 1998 Papua New Guinea tsunamis. Nat Hazards 21:1-21

Sassa K, Dang K, Yanagisawa H, He B (2016) A new landslide-induced tsunami simulation model and its application to the 1792 Unzen-Mayuyama landslide-and-tsunami disaster. Landslides 13(6):1405-1419

Slingerland R, Voight B (1982) Evaluating hazard of landslide-induced water waves. J Waterw Port Coastal Ocean 108(4):504-512

Synolakis CE, Raichlen F (2003) Waves and run-up generated by a threedimensional sliding mass. In Submarine mass movements and their consequences Springer, Dordrecht 113-119

Synolakis CE, Bardet JP, Borrero JC, Davies HL, Okal EA, Silver EA, Sweet S, Tappin DR (2002) The slump origin of the 1998 Papua New Guinea tsunami. Proc R Soc Lond A 458(2020):763-789

Synolakis CE (2003) Tsunami and seiche. In: Chen WF, Scawthorn C (eds) Earthquake engineering handbook. CRC Press, Boca Raton, FL, pp 1-90 (Chapter 9)

Takagi H, Pratama MB, Kurobe S, Esteban M, Aránguiz R, Ke B (2019) Analysis of generation and arrival time of landslide tsunami to Palu City due to the 2018 Sulawesi earthquake. Landslides 16(5):983-991

Tappin DR, Watts P, Grilli ST (2008) The Papua New Guinea tsunami of 17 July 1998: anatomy of a catastrophic event. Nat Hazards Earth Syst Sci 8(2):243-266

Tinti S, Armigliato A, Manucci A, Pagnoni G, Zaniboni F, Yalçiner AC, Altinok $Y$ (2006) The generating mechanisms of the August 17, 1999 Izmit bay (Turkey) tsunami: regional (tectonic) and local (mass instabilities) causes. Mar Geol 225(1-4):311-330

Tinti S, Tonini R (2013) The UBO-TSUFD tsunami inundation model: validation and application to a tsunami case study focused on the city of Catania, Italy. Nat Hazards Earth Syst Sci 13:1795-1816

Watts P (2000) Tsunami features of solid block underwater landslides. J Waterw Port Coast Ocean Eng 126(3):144-152

Watts $P$ (1998) Wavemaker curves for tsunamis generated by underwater landslides. J Waterw Port Coast Ocean Eng 124(3):127-137

Watts P (1997) Water waves generated by underwater landslides. PhD thesis, California Institute of Technology, Pasadena, California

Watts P, Grilli ST, Kirby JT, Fryer GJ, Tappin DR (2003) Landslide tsunami case studies using a Boussinesq model and a fully nonlinear tsunami generation model. Nat Hazards Earth Syst Sci 3(5):391-402

Watts P, Grilli ST, Tappin DR, Fryer GJ (2005) Tsunami generation by submarine mass failure. II: predictive equations and case studies. J Waterw Port Coast Ocean Eng 131(6):298-310

Wessel P, Smith WH (1998) New improved version of Generic Mapping Tools released. Eos Trans AGU 79(47):579

Wiegel RL (1955) Laboratory studies of gravity waves generated by the movement of a submerged body. Eos Trans AGU 36(5):759-774

\section{Ramtin Sabeti $(\bowtie) \cdot$ Mohammad Heidarzadeh}

Department of Civil and Environmental Engineering, Brunel University London, Howell Building, Room 308, Uxbridge UB8 3PH, UK

Email: ramtin.sabeti@brunel.ac.uk 